\title{
Conditional inversion and GIVENNESS*
}

\author{
María Biezma \\ UMass Amherst
}

\begin{abstract}
This paper provides support for the claim that non-canonical word-order adds "extra meaning" to natural language utterances (Prince). In particular, it tells us about the informational status of the constituents. The case study in this paper is subject-auxiliary inversion in conditional antecedents. I argue that subjectauxiliary inversion in conditional antecedents indicates that the antecedent is GIVEN (Schwarzschild 1999). This proposal explains further pragmatic inferences such as why inverted conditionals are particularly good as reproaches.
\end{abstract}

Keywords: Non-canonical word-order, conditionals, pragmatics, discourse, GIVEN.

\section{On non-canonical word-order}

It is commonly assumed that the meaning of an utterance depends on the composed meaning of its parts and the context in which it is uttered. In this paper I present evidence supporting the claim that other factors are also important when it comes to understanding natural language utterances. On the basis of a case-study, I provide evidence supporting Prince's claim that non-canonical word-order encodes extrainformation regarding the discourse status of constituents. ${ }^{1}$ The case-study is subjectauxiliary inversion in conditional antecedents in English (1) and Spanish (2).

(1) English

a. If I had been offered the job, I would have brought champagne.

b. Had I been offered the job, I would have brought champagne.

(2) Spanish

a. Si me hubieran ofrecido el trabajo, habría traído champán. if cl.1.s.D had.3.pl offered the job have.1.sg.P brought champagne 'If they had offered me the job, I would have brought champagne'

b. Me hubieran ofrecido el trabajo, habría traído champán. cl.1.s.D had.3.pl offered the job have.1.sg.P brought champagne 'Had they offered me the job, I would have brought champagne'

* Thanks to Chris Potts, Rajesh Bhatt and Lyn Frazier for comments. Thanks specially to Rajesh for being the first to point out to me the work of Ellen Prince.

1 See Prince (1992, 1996), Birner \& Ward (1998), Ward \& Birner (2004), Birner (2006) a.o. 
(1a) and (1b), as well as (2a) and (2b), have the same truth-conditions. However, as Iatridou \& Embick (1994) (henceforth I\&E) have pointed out, they are not discoursively interchangeable. In the following sections I argue that in order for a conditional with subject-auxiliary inversion in the antecedent (henceforth inverted conditionals) to be felicitously uttered, the antecedent has to be GIVEN in Schwarzschild's (1999) terms. This notion of givenness does not require that the antecedent proposition be part of the Common Ground, but rather that it have been 'entertained' (in a colloquial sense). I will also show that this proposal explains further pragmatic effects, namely why inverted conditionals are particularly good as reproaches.

The paper is organized as follows: in \$2 I start by reviewing assumptions regarding the syntax of conditionals. The main goal of this section is to show that inversion in conditionals is not the same kind of movement found in questions and hence that the claims made in this paper regarding inversion in conditionals are not meant to hold for questions. In $\$ 3$ I discuss the discourse conditions of inverted conditionals and review arguments presented in I\&E. Since there is already a proposal in the literature for English, I focus on data from this language for the sake of concreteness and clarity. However, everything said about English in this section can also be said about Spanish. ${ }^{2}$ In $\$ 3.2$ I propose that for inverted antecedents to be felicitous, the antecedent has to be GIVEN. I illustrate this by looking at the discourse, §3.2.1, and also world knowledge, §3.2.2. In particular, I illustrate how known dependencies between facts (laws, Veltman 2005) can also serve as antecedents for GIVENNESS and license inversion. In the rest of the section I explore remaining arguments in I\&E. In §4 I explore the use of inverted conditionals as reproaches and specially focus on Spanish inverted conditionals. I tackle both the case of regular inverted conditionals like (2b) and the case of special inverted conditionals in which only the antecedent is spelled out and the 'missing' consequent is desired (a special kind of Spanish optatives, ${ }^{3}$ see Biezma 2011b,a).

$$
\begin{aligned}
& \text { Haber salido antes. [HPC] } \\
& \text { have.Inf left earlier } \\
& \text { 'Had you left earlier, you would have arrived on time' }
\end{aligned}
$$

Biezma (2010, 2011a) dubs conditionals like (3) HPC (the only thing that is spelled out is the auxiliary $H($ aber $)$ and a $P($ articiple $) C$ (lause $)$ ) and I also adopt this termi-

2 This does not mean that the meaning of inversion is the same across languages in general. It does happen to be the same in English and Spanish, see $\$ 5$.

3 In Biezma (2011b,a) I defend an account of optatives in which desirability in optatives is derived from the fact that optatives are conditionals and from the presence of a scalar focus particle scoping over and associating with the antecedent proposition. HPCs differ from regular optatives regarding the need to have an overt scalar adverb, although HPCs show also scalar phenomena. 
nology here. ${ }^{4}$

In this section I show that by taking into consideration the meaning of inversion and paying attention to relevant constraints we can explain why inverted conditionals are particularly good as reproaches. Finally, in \$5 I take up a more general question: why does inversion mark that the antecedent is GIVEN?

\section{Syntactic assumptions}

In what follows I assume a relatively simple "default account" of the syntax of conditionals and inversion. It is sketched in (4), where I follow Pesetsky (1989) in characterizing inversion as T-to-C movement.

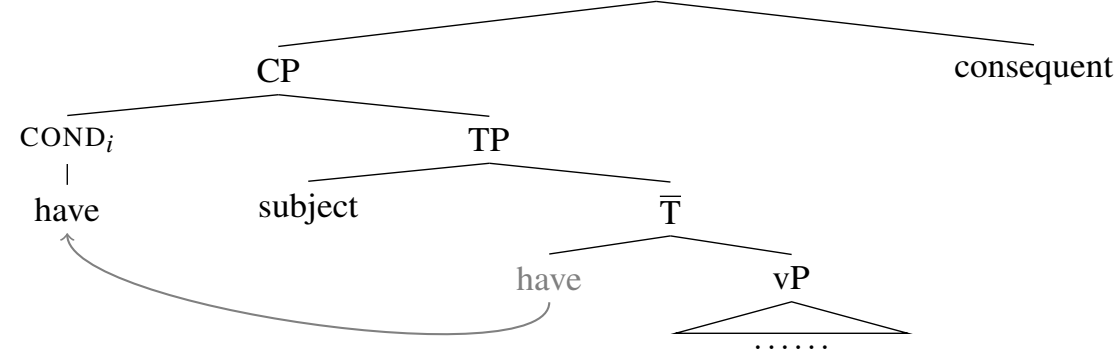

According to Rawlins (2008) a.o., there is no need to make any significant assumption about the LF of a conditional sentence. I assume that $I f$-clauses are restrictors of the domain of quantification of the modal (Lewis 1973; Kratzer 1977; Heim 1982: a.o.), i.e. the conditional adjunct establishes some temporary assumptions restricting the context used for the evaluation of the modal. In Rawlins's (2008) account, the restriction of the context is mediated by an interpretable feature in C, COND. COND restricts the context in which the consequent clause is evaluated. ${ }^{5}$ The complementizer if is compatible with COND and phonologically realizes it. When if is not part of the numeration, there is movement of the auxiliary to $\mathrm{C}$, and COND is phonologically realized by the auxiliary. The auxiliary moves to $\mathrm{C}$ possibly because of the need to phonologically realize the feature $\operatorname{COND}_{i} \cdot{ }^{6}$

I\&E offer a series of empirical observations regarding conditional inversion across languages. For example, they observe that there is language variability with

4 Bosque (1980) proposes a characterization of HPCs as (retrospective) imperatives. In Biezma (2010, 2011a) I show that an analysis along those lines is actually not viable: it fails on morphosyntactic grounds and does not explain pragmatic inferences made when HPCs are uttered. (See $\S 4$ ).

5 The feature is not restricted to conditionals and thus it is not exclusive to conditional complementizers like if. The claim is that a feature like this is needed in the grammar independently of conditionals to analyze other constructions in which there is a domain restriction. See Rawlins (2008) for details. 6 See Pesetsky (1989) for arguments in favor of inversion as movement from $\mathrm{T}$ to $\mathrm{C}$. 
respect to the type of conditional in which inversion is allowed. While English only allows inversion in counterfactual conditionals, ${ }^{7}$ German allows inversion also in indicative conditionals. Languages vary not only regarding which conditionals may have inverted antecedents, but also with respect to other possible T-to-C movements. The data seems to suggest that for a language to have subject-auxiliary inversion in conditionals, it also needs to allow inversion in questions (although the reasons are unclear). However, this correspondence does not work in the other direction: not all languages in which there is movement from $\mathrm{T}$ to $\mathrm{C}$ in questions allow conditional inversion. This seems to indicate that movement to $\mathrm{C}$ in questions and in conditionals is different: the movement is triggered for independent reasons and, arguably, to different positions within the $\mathrm{CP}$ domain. Let us briefly review some differences.

In questions, movement from $\mathrm{T}$ to $\mathrm{C}$ is not subject to the constraints we observe in conditionals. Both auxiliaries and modals in general move to $\mathrm{C}$ as in (5). However, not every modal can invert in conditionals, see (6).

a. Have you gone to the supermarket?

b. Should you go to the supermarket?

c. Could you go to the supermarket?

(6) a. Had you to gone to the supermarket, you would have bought artichokes.

b. Should you go to the supermarket, you wouldn't have to go to the bakery.

c. *Could you go to the supermarket, you wouldn't have to go to the bakery.

English questions and conditionals also behave differently with respect to contracted negation. Inverted counterfactuals do not allow contracted negation, whereas contracted negation is possible in questions (Iatridou \& Embick 1994: ex.8).

(7) a. Hadn't he seen the car coming?

b. *Hadn't he seen the car coming, he would have been killed.

c. Had he not seen the car coming, he would have been killed.

Rawlins (2008) offers arguments from (un)conditionals in favor of a COND feature being located in a position different from the $\mathrm{Q}$ feature. In particular, Rawlins argues that the COND feature is located above the $\mathrm{Q}_{i}$ feature (responsible for movement in questions). This seems to fit the emerging picture. If movement from $\mathrm{T}$ to $\mathrm{C}$ in questions were exactly the same movement we find in counterfactuals, motivated by the same factors and targeting the same position, we would expect the same

7 I am using the term counterfactual to make reference to the presence of past tense and perfect aspect in the antecedent. This is not a claim about the truth-value of the antecedent proposition. In the literature, the term 'subjunctive conditional' is sometimes used in this way. 
properties. However, as observed when looking at the behavior of modals and contracted negation, we do not find the same properties. ${ }^{8}$

To summarize, languages allowing movement from $\mathrm{T}$ to $\mathrm{C}$ in questions may also allow movement from $\mathrm{T}$ to $\mathrm{C}$ in counterfactual conditionals. However, the movement from $\mathrm{T}$ to $\mathrm{C}$ in counterfactual conditionals seems to be different from movement from $\mathrm{T}$ to $\mathrm{C}$ in questions. Thus my discussion of the properties of inversion in this paper is restricted to the case of conditionals. It does not apply to questions.

\section{The discourse status of the antecedent}

In this section I argue that conditional inversion indicates that the antecedent is GIVEN (Schwarzschild 1999). This goes against I\&E's proposal, who argued that inversion in subjunctive conditionals indicates that the falsity of the antecedent proposition is part of the common ground (a presuppositional account). I briefly review the details of I\&E's proposal in $\$ 3.1$. In $\$ 3.2$ I argue that counterfactuality is an implicature even when there is inversion. I offer data supporting the view that inversion in conditionals indicates that the antecedent is GIVEN (which does not require that anything be part of the common ground). I support this hypothesis with examples related to preceding discourse and world knowledge, in particular dependencies between facts (laws, Veltman 2005). The remainder of $\S 3$ is devoted to showing that other arguments in I\&E are also problematic.

Since I will discuss a proposal regarding the meaning of inversion in English, in this section I focus mainly on English. However, the claims made for English in this section can also be made about Spanish.

\subsection{A presuppositional account}

To my knowledge, I\&E were the first to argue that subject-auxiliary inversion in conditional antecedents is not a mere stylistic variant with respect to regular if-conditionals. I\&E claim that inverted antecedents involve old information, specifically that the truth-value of the proposition in the antecedent is known to be false at the utterance time. They support their claim with the following scenario (based on a suggestion by Eric Reuland): "You arrive at the house of friends, who know that you have just been to a job interview but do not know the results. Uttering

8 The differences between questions and conditional adjuncts are also explored in Bhatt \& Pancheva 2006. In particular, these authors argue that the fact that counterfactual conditionals allow inversion more widely than indicative conditionals seems to indicate that questions and conditional adjuncts do not go hand in hand (i.e. if conditional adjuncts and questions were alike with respect to inversion, it would be hard to explain why inversion is more widely allowed in counterfactual conditionals than in indicative conditionals, while it is possible in questions in general). 
(8a) at the dinner table would be a (characteristically witty) potential conversational move, but ( $8 b$ ) would, as Bernhard Rohrbacher (p.c.) put it, leave some of the people present wondering why they had been left out of a previous announcement about the interview results:"

(8) a. If I had been offered the job, I would have brought champagne.

b. Had I been offered the job, I would have brought champagne.

Considering (8), I\&E claim that what is backgrounded as old information in an inverted subjunctive conditional $\operatorname{Had} \alpha, \beta$ is $\neg \alpha$, i.e. that it is part of the Common Ground that the antecedent proposition is false, (9).

(9) Had I been offered the job, I would have brought champagne.

Old Information: I was not offered the job

This idea is also taken up by Horn (2000), who uses I\&E's data and analysis to support a more general view of inversion as licensed for pragmatic reasons. ${ }^{9}$

\subsection{An implicature account}

The claim that $\neg \alpha$ is old information amounts to saying that $\neg \alpha$ is part of the common-ground and thus that counterfactuality in inverted conditionals is not an implicature (as it is in non-inverted conditionals) but a presupposition. If this were true, counterfactuality couldn't be cancelled in inverted conditionals.

Counterfactuality has been considered an implicature since Anderson (1951):

(10) "In the investigation of Jones' death, a doctor might say "If Jones had taken arsenic, he would have shown just exactly those symptoms which he does in fact show". Now in this context the doctor's statement would probably be taken as lending support to the view that Jones took arsenic - it would certainly not be held to imply that Jones did not take aresenic."

In the example in (10) the conditional is used to support the view that Jones took arsenic. Counterfactuality is thus cancelled, indicating that it is an implicature.

If inverted antecedents presupposed that the proposition in the antecedent is false, it would not be possible to cancel counterfactuality. Is this what we find? The impression is that the counterfactual in (11), uttered as a response to the suggestion that Jones might have taken arsenic, is as acceptable as its non-inverted counterpart. This indicates that counterfactuality is an implicature also in inverted conditionals and not a presupposition. ${ }^{10}$

9 According to Horn (2000), the inversion of an element marks it as pragmatically presupposed, "in particular as salient, 'Chafe given' (Prince 1981) or consciousness-presupposed (Lambrecht 1994)."

10 Notice that here I am imposing a discourse constraint in order to accept the inverted conditional. This requirement finds justification below. 
(11) Had Jones taken arsenic, he would have shown just exactly those symptoms which he does in fact show

In sum, the contrast between inverted and non-inverted conditionals does not concern the implicature vs. presupposition status of counterfactuality.

Consider now the contrast in (12). In this scenario the utterance of an inverted conditional is not good (Ann) whereas the regular conditional is fine (Ann').

(12) Ann, John, and Peter are having coffee together chatting about holiday plans. Abruptly changing the topic, John starts talking about Maria, who everybody knows was having a job interview today.

John: I just saw Maria buying a special dijon mustard at the store.

Ann: Mm... \#Had Maria gotten the job, she would have bought dijon to cook her favorite dish.

Ann': Mm... If Maria had gotten the job, she would have bought dijon to cook her favorite dish.

Consider now the alternative dialogue in (13) in the scenario in (12).

(13) John: I just saw Maria buying a special dijon mustard at the store.

Ann: She must have gotten the job.

Peter: What does buying dijon have to do with the job?

Ann: Had Maria gotten the job, she would have bought dijon to cook her favorite dish. So it is quite likely that she did!

The contrast between the acceptability of the inverted antecedent in (13) ${ }^{11}$ versus the oddness in (12) indicates that, for inverted conditionals to be felicitous, special discourse conditions need to be met. Intuitively, the claim is that conditionals with inverted antecedents are good only if the alternative expressed in the antecedent has already been entertained (in this case, Maria's getting a job has been entertained).

The scenario in (14) makes the same point with a different example:

(14) A: I wonder if Maria is at the meeting.

B: I just saw John coming out of the conference room smiling.

A: Well, then she is probably not there.

B: Why do you say that?

A: Had she been there, John would not have been that happy.

11 As in (10), the acceptability of the dialogue in (13), in which it is established that possibly Maria has gotten the job, indicates that in inverted antecedents counterfactuality is an implicature, since it can be cancelled. 
The point in the scenario above, again, is that at the end of the dialogue we do not really know the status of the proposition in the antecedent. It may or may not be true that Maria is attending the meeting. Inversion does not indicate that the proposition in the antecedent is established as false. As before, what matters is that the alternative presented in the antecedent proposition has been entertained before the utterance of the inverted conditional.

One immediate prediction of the proposal made here is that inverted conditionals are not good out of the blue. This is not predicted for regular conditionals. (15) shows that the prediction is borne out.

(15) A enters the room with the newspaper in his hand:

$\mathrm{A}_{1}$ : ? You know, had you bought tickets for tonight's basketball game, you could resell them for a fortune.

$\mathrm{A}_{2}$ : You know, if you had bought tickets for tonight's basketball game, you could resell them for a fortune.

With no previous discussion of tickets, $A_{1}$ 's utterance is somewhat odd, while $A_{2}$ 's is not. It is true that, given accommodation, judgements on inverted antecedents can be hard. We can try to make sense of $A_{1}$ in (15) by assuming that there was previous talk about the addressee buying tickets for tonight's game. However, if we understand that what triggered $\mathrm{A}_{1}$ 's utterance was simply something on a sports page, $A_{1}$ 's utterance is not good.

To sum up, inversion is a strategy to relate an utterance to the previous discourse: it marks the antecedent proposition as previously considered/entertained. Inversion refers to the status of the proposition with respect to the discourse dimension. I will cash this out by appealing to GIVENNESS. In what follows I sketch Schwarzschild's (1999) concept of GIVEN and show that this is the relevant concept for inverted conditionals: the antecedent proposition has been "entertained" when the antecedent is GIVEN.

\subsubsection{GIVENNESS and the discourse}

Schwarzschild's (1999) concept of GIVEN is different from some other ways of understanding givenness. This is a preliminary intuitive definition (Schwarzschild's def 14):

(16) An utterance is GIVEN iff it is entailed by prior discourse.

The concept of GIVEN proposed by Schwarzschild does not require that anything be known or true, it just requires that something be entailed by a 'piece of language' in the previous discourse. Since GIVEN involves an entailment relationship, certain 
type-shifting is required to obtain relationships between propositions. Let us look at GIVEN in more detail.

(17) An utterance U counts as GIVEN iff it has a salient antecedent $\mathrm{A}$ and

a. if $\mathrm{U}$ is type e, then $\mathrm{A}$ and $\mathrm{U}$ corefer;

b. otherwise: modulo $\exists$-type shifting, A entails the Existential F-closure of $\mathrm{U}$.

(18) Existential F-Closure of $U=_{d f}$ the result of replacing F-marked phrases in $\mathrm{U}$ with variables and existentially closing the result, modulo existential type shifting.

When the antecedent has been previously uttered in the discourse, there is no mystery in showing that it is GIVEN according to (17), so I leave this case aside. An interesting prediction made by (17) is that for an inverted conditional to be felicitous there is no need to find an exactly matching antecedent in the discourse. I illustrate this with Spanish below, but speakers concur in that the English version is also good:

(19) A is telling a friend that there had been problem with the pipes in her house, and water had been pouring into the living-room for hours because she did not know what to do.

B: Deberías haber llamado a Javier. Él y su hermano Pablo posiblemente estaban en casa y son muy manitas.

'You should have called Javier. He and his brother were probably home and either could have helped.'

A: No, Javier se fue de vacaciones.

'No, Javier was on vacation'

B: Bueno, hubieras llamado a Pablo, él también te habría ayudado. well had called to Pablo he too cl.2 would have helped

'Well, had you called Pablo, he would have been able to help you too'

The antecedent of the inverted conditional in (19), hubieras llamado a Pablo... ('had you called Pablo...') does not have a perfectly matching antecedent, and yet the inverted conditional is fine.

(20) In a discourse where llamar a Javier ('call Javier') has been uttered, llamar $a[\text { Pablo }]_{\mathrm{F}}$ ('call Pablo') should count as GIVEN:

i. $\quad \exists$-type shifting of [llamar a Javier] yields: $\quad \exists y[y$ llamar a Javier]

ii. Replace F-marked part of llamar a $[\text { Pablo }]_{\mathrm{F}}$ with variable: [ llamar a X]

iii. $\exists$-type shifting of [llamar a X] yields: $\quad \exists y[y$ llamar a $\mathrm{X}]$ 
Conditional inversion and GIVENNESS

$$
\begin{array}{lll}
\text { iv. } \exists \text {-binding F-variable gives: } & & \exists \mathrm{X} \exists y[y \text { llamar a } \mathrm{X}] \\
\text { v. } \exists y[y \text { llamar a Javier }] & \text { ENTAILS } & \exists \mathrm{X} \exists y[y \text { llamar a } \mathrm{X}]
\end{array}
$$

The utterance of an inverted conditional is good even though the antecedent does not find a perfect match in the discourse. It just needs to be GIVEN. ${ }^{12}$

\subsubsection{GIVENNESS and laws}

Schwarzschild's (1999) GIVEN is also meant to apply when there is no overt antecedent and the antecedent is supplied by context. This is what we observe in (21). In this case the background knowledge acting as the antecedent of the utterance is knowledge about dependencies between facts in the world.

(21) Tom is home with pneumonia because he went for a walk to the mountain without a coat and temperatures were below $0^{\circ} \mathrm{F}$. He told this to Sam, to whom he is now complaining.

Tom: Oh my! I am so sick!

Sam: Te hubieras puesto un abrigo, no te habrías resfriado. cl.2.sg.Dat had.2.sg put on a coat neg cl.2 would have cold 'Had you worn a coat, you wouldn't have caught a cold'

Sam': Haber-te puesto un abrigo. [HPC] have.Inf.-cl. 2 worn a coat 'Had you worn your coat'

There is no mention of wearing a coat in the previous discourse. However, it is well known that if you wear a coat when it's cold, you don't get a cold. This kind of dependencies between facts (wearing a coat-not getting a cold) is what we call laws (see Veltman 2005 for details). When uttering the inverted conditional, the speaker is invoking the well-known law. The scenario in (22) shows that laws are also relevant for conditional inversion in English.

(22) Mom gets back after a week-long business trip. As she enters the house she can see right away that her child has not done his chores for the day: the garbage is in and the dishes are dirty. As she is putting down her bags, her child appears on his way out.

Child: Hi mom! Bye mom!

Mom: Where are you going?

12 Notice that the antecedent proposition does not need to have been previously entertained in relation to the consequent. All that is needed is that the antecedent itself be GIVEN. I set this issue aside in this paper for space reasons. 
Child: I'm going to the mall with my friends.

Mom: You are not allowed to go anywhere. Had you done your chores, you would be able to go with your friends. But since you haven't, you are grounded.

In the small exchange above, the mother is appealing to the well-known generalization operating in the household that if the child does not do his chores, he is not allowed to go with his friends. We have inversion even though there is no previous discourse that makes the antecedent GIVEN. Rather, inversion is licensed by the contextually supplied law.

\subsubsection{Explaining the data}

I have claimed that inversion in subjunctive conditional antecedents in English and Spanish indicates that the antecedent has been entertained, construing this as GIVEN in Schwarzschild's (1999) terms. In this, I depart from I\&E, who claim that inversion indicates that the truth-value of the antecedent proposition is already known to be false, i.e. it is presupposed that the antecedent proposition is false. However, I haven't explained why speakers might have the intuitions that I\&E report with respect to (8). According to the proposal made here, the oddity of (8b) is due to the unfounded assumption that the alternative in the antecedent has already been entertained, whereas according to I\&E's proposal, the oddity of ( $8 b)$ is due to the unsatisfied presupposition that the antecedent proposition is false. Given my proposal, the problem raised by (8b) is why are we assuming that the alternative expressed by the proposition has already been entertained?, whereas in I\&E's account the problem is why are we assuming that the proposition in the antecedent is false? Example (8) seems to support I\&E, since the speaker of (8b) appears to take for granted that he did not get the job and that this is already known by the audience. How is this intuition explained here?

I\&E's example in (8) is biased towards the falsity of the proposition in the antecedent, but this is not a bias of the inverted conditional construction per se but rather a bias brought about by the use of a first person pronoun. One imagines that if there is anyone who knows whether they have been offered a job or not, it is the person to whom the job may have been offered. And yet, the speaker uses a counterfactual conditional with the implicature that it is false that he/she was offered the job. If we consider the use of a first person in (8b), together with the meaning of inversion argued for above and the fact that the construction is counterfactual (implying that the antecedent is false), the conclusion is a strong inference that the antecedent is in fact false. It is hard not to reach this conclusion when the person most interested in getting the job implies that he/she didn't. Indeed, if we change (8) 
to a third person the bias towards the falsity of the antecedent diminishes. ${ }^{13}$ Let us examine (23).

(23) (A and B are chatting while looking at John, who is a little distance away)

A: I wonder if John got the job.

B: Well, had he gotten the job, he would be behaving exactly as he is doing. So, he probably did.

B': Well, had he gotten the job, he wouldn't be here drinking. So he probably didn't. But we should make sure. Go ask him.

Nothing is clear/resolved regarding whether John has or has not been offered the job in either of these examples. This indicates that the strong counterfactuality noted by I\&E is associated with the first person, and not with the meaning of inversion. ${ }^{14}$

To sum up, inversion in counterfactual conditionals does not signal that the antecedent proposition is known to be false at the time of utterance. Inversion in English and Spanish counterfactual conditionals carries the pragmatic presupposition that the antecedent proposition had been previously entertained in the discourse. The impact of inversion in the English examples, just as in the case of Spanish, is to link the antecedent to previous discourse or background knowledge.

I\&E derived other differences between inverted and non-inverted conditionals from their initial idea that inversion indicates that the antecedent proposition is known to be false. Since that initial hypothesis doesn't hold, we need to explain the remaining differences in some other way. In what follows I review the facts pointed out in I\&E and account for them without appealing to a falseness presupposition.

\subsection{Focus adverbs}

There are differences between inverted an non-inverted conditional antecedents with respect to the distribution of focus adverbs (see (24), I\&E's ex. (20-21)).

a. i. Even if she had been allergic to dill, he would (still) have served the stuffed grape leaves.

ii. Only if Peter had come, would Susan have left.

b. i. * Only had I thought that he was sick, would I have called him.

ii. ? Even had Joe served truffles, Kathy would not have been happy.

13 Some English speakers find the example below difficult. However, they find the non-inverted version as difficult. This seems to indicate that the problem is not related to inversion, but rather to a strong counterfactuality inference across the board in counterfactual conditionals.

14 In I\&E's example the bias is even stronger since there is no champagne, which is what the speaker says he would have brought if he had gotten the job. 
In I\&E's account, the impossibility of having focus adverbs in inverted conditionals is a consequence of the hypothesis that inversion in conditionals signals that the antecedent proposition is old information. They argue that old information cannot be focused and, since in inverted conditionals the antecedent proposition is old information, inverted antecedents do not allow focus adverbs.

However, Horn (2000) provides us with counterexamples to I\&E's claim:

(25) * Only had this match been struck, it would have lit.

(26) *Is this match struck, it will light. [i.e. If the match is struck, it will light]

(27) Even had this match been struck, it (still) wouldn't have lit. (Goodman 1947)

(28) Had this match been struck, it would have lit.

(27) shows that focus adverbs can be present when there is inversion. ${ }^{15}$ Horn (2000) does not claim that old information is incompatible with focus adverbs. His explanation for why some focus adverbs can appear with inverted antecedents and others can't has to do with the specific semantics of the adverbs (the reader is referred to Horn 2000 for details).

In sum, the problem with focus adverbs is not why they are not possible in inverted conditionals. The actual question is why some are licensed but others are not. Horn (2000) provides us with a pragmatic explanation for the contrasts. Regardless of whether we wish to adopt Horn's (2000) account or not, the fact is that inverted conditionals do allow focus adverbs, as we have seen with even. Hence, even if we were to accept I\&E's proposal that inverted antecedents represent old information, it would not follow that old information cannot be focused. I have nothing to add about the semantic differences between only and even in this paper.

\subsection{Question/answer pairs and clefts}

By claiming that the antecedent of an inverted conditionals cannot be focused, I\&E predict that inverted antecedents cannot be answers to questions and that they cannot be clefted. I\&E offer the data in (29) to illustrate differences between regular conditional antecedents and inverted conditional antecedents. On the basis of the data in (29) (I\&E ex. (31)), they claim that regular antecedents can serve as answers to questions, whereas inverted antecedents cannot. ${ }^{16}$

(29) A: When/Under what circumstances would Mary have come?

B: If she had been offered many artichokes.

15 Horn's own take on inversion does not prevent inverted conditionals from allowing focus adverbs. 16 Both utterances by B are understood to have final falling intonation. 
B': \# Had she been offered many artichokes.

Question/answer pairs are often used to identify sentence focus. ${ }^{17}$ The proposition embedded under the question operator is the topic and the constituent giving value to the variable (wh-phrase) in the question is the focus. Since regular conditional antecedents can work as answers to questions, I\&E consider that regular conditional antecedents can be focused. They argue, by looking at (29), that inverted conditional antecedents are not answers to questions. They take this as evidence that they cannot be focussed.

Notice that the data in (29) above indicates that (29B) is good as an answer to a question with final falling intonation and (29B') is bad. However, (29B') becomes much better once we spell out the consequent.
A: When/Under what circumstances would Mary have come?
B": Had she been offered many artichokes, she would have come.

The fact that (29B') becomes much better with the consequent spelled out indicates that what goes wrong in (29B') is not inversion in relation to focus. Notice also that the consequent in (30B") is heavily de-accented, signaling that it is not new information. This means that the presence of the consequent is not required for information structure reasons: the consequent is not there for reasons of information, but rather for morphosyntactic reasons.

If we change the discourse conditions in which an inverted conditional is uttered as a response to a question, and spell out the consequent, it becomes completely fine:

A: We need to find out what we did wrong with Mary, so we do not repeat the same mistakes with the next job candidate and again have our job offer turned down.

B: Hum! We did not offer Mary things that she would have considered attractive.

A: Yeah! We did not made her a very attractive offer. Mary loves artichokes. That would have made a difference.

B: Let's write these things down. Under what circumstances would Mary have come?

A: Well, had she been offered many artichokes, she would have come.

$17 \mathrm{I} \& \mathrm{E}$ are not explicit regarding what they understand as focus. I am making as safe an assumption as possible. We just understand sentence focus in opposition to sentence topic. There are constructions in which a certain constituent is marked as focused, as in answers to questions, in which the focus of the answer must correspond to the wh-phrase of the question, or in clefts, in which focus corresponds with the clefted phrase. 
As predicted by my proposal regarding the meaning of inversion in conditionals, when the discourse conditions are such that the antecedent proposition has been entertained beforehand, the utterance of the inverted conditional is fine.

The discussion above indicates that the reason that antecedents with subjectauxiliary inversion cannot stand on their own is syntactic. The evidence suggests that it has nothing to do with focal properties. Indeed, even when we have an acceptable focus adverb, as in (27), the conditional is not accepted if the consequent is not present, (32).

(32) *Even had this match been struck

The claim that the crucial factor regarding the impossibility of (29B') is syntactic is supported by the cleft data in (33) (I\&E ex. (27)):

(33) a. It is if John had come that Mary would have left.

b. *It is had John come that Mary would have left.

Clefting the antecedent of a regular conditional is fine, but clefting an inverted antecedent is not. I\&E argue that this supports their claim that inverted antecedents cannot be focused. However, I have argued above that (29B') and (30B') illustrate a syntactic constraint concerning inverted conditionals (not present in non-inverted conditionals): the consequent must be syntactically present. Regular if-clauses are free standing constituents, whereas inverted antecedents need to be embedded in a larger structure. The cleft data in (33) are congruent with the claim that inverted antecedents need to be licensed by the overt presence of the consequent. ${ }^{18}$

The fact that there is a difference between regular if-clauses and inverted antecedents with respect to their ability to stand alone holds not only in English, but also in German.
A: When/Under what circumstances would Mary have come?
B: Wenn man ihr viele Artischocken angeboten hätte.
'If we had offered her artichokes'
B': \#Hätte man ihr viele Artischocken angeboten.
'Had we offered her more artichokes'

An explanation for this fact regarding inversion goes beyond the scope of this paper. The important point is the impossibility of inverted antecedents to stand on their own and thus be answers to questions or be clefted.

18 In Biezma 2010 I investigate the case of a special type of Spanish optative and show that they are inverted conditionals with consequents that are not spelled out. In Biezma 2011a I discuss crosslinguistic differences regarding the spelling out of consequents. 


\subsection{Conclusion}

In this section I have argued that inversion in English and Spanish conditional antecedents indicates that the antecedent proposition has been previously entertained in discourse and, more specifically, that the antecedent is GIVEN in Schwarzschild's (1999) terms. This claim amounts to saying that the choice between inverted and non-inverted conditionals is not merely stylistic variation, as I\&E already noticed. The current proposal is different from the proposal in I\&E, where it is argued that inversion in conditionals indicates that the antecedent proposition is known to be false, i.e. that the truth value of the antecedent proposition is old information, and further argued that inverted conditionals show that old information cannot be focused. I\&E's arguments are based on the apparent impossibility of finding focus adverbs in inverted conditionals, and on the apparent impossibility of using inverted conditionals as answers to questions. However, I have proposed alternative explanations for I\&E's observation based on a more fine-grained discussion of adverb data, syntactic constraints and discourse structure.

\section{Duh!: Reproaching and scolding the addressee}

The study of what inversion means in English and Spanish is interesting in its own right, but it becomes even more interesting when it aids our understanding of pragmatic inferences that otherwise may need to be explained via conventionalization. Let us look at the examples in (35) again, in a context like (21) in which the addressee is whining about being sick after going for a walk without a coat on a cold night.

a. Te hubieras puesto un abrigo, no estarías enfermo.

cl.2 had.2.sg worn a coat neg would-be sick

'Had you worn a coat, you would not be sick'

b. Haber-te puesto un abrigo. [HPC]

have.Inf.-cl.2.sg worn a coat

'Had you worn a coat...'

When inverted conditionals like the ones in (35) are uttered in scenarios like (21), an extra inference is made: these inverted conditionals are understood as reproaches. Indeed, a more accurate translation of the responses in the scenario in (21), repeated in (35), would be (36).

Duh! Had you worn a coat, (you wouldn't be sick).

In the scenario in (21), GIVENNESS arises because of a well known law. However, this is not necessary to obtain a reproach effect. The effect could also have arisen if the sick person had been advised to wear a coat but did not do it. The utterance 
of the non-inverted conditional does not trigger the same reproach inferences. It is certainly not nice to point out the obvious, but the effect is not the same reproach inference as the one triggered by inversion.

Inverted conditionals in English are also well suited for reproaches. English speakers find inverted conditionals specially good in reproach situations like (22).

(22) Mom: Had you done your chores, you would be able to go with your friends.

Why do we infer a reproach from the use of an inverted conditional? Certainly this is not something that inversion itself encodes: not all inverted conditionals are understood as reproaches. A speaker reproaches the addressee if he/she holds him/her responsible for some undesirable state of affairs. Inverted conditionals are understood as reproaches only if the consequent is false but desired, the addressee could have brought about the truth of the antecedent proposition and the proposition was prominent at the time the addressee decided to do something else (either it was advised or world knowledge indicated that it was the thing to do). ${ }^{19}$ By means of inversion, the speaker reminds the addressee that the antecedent proposition leading to the desired state of affairs was prominent.

Aided by the meaning carried out by subject-auxiliary inversion in subjunctive conditionals and paying attention to more fine grained contextual constraints, we can find an explanation for pragmatic inferences without conventionalization. ${ }^{20}$

\section{Why inversion?}

The proposal made in this paper differs from the view in Horn (2000). However, it is interesting to see what Horn says about why inversion signals a (pragmatic) presupposition (Horn 2000: 157).

"As to why inversion SHOULD mark pragmatic presupposition, a natural functional speculation would depict non-canonical wordorder as a signal of non-asserted clausal material, whether it may be interrogative, exclamative, or (as here) presupposed."

Inversion in conditional antecedents is an optional operation and carries a meaning. ${ }^{21}$ It is not strange for natural language to perform an operation on an auxiliary to mark

19 Notice that in HPCs it is always the case that the consequences of the antecedent proposition are desired at the time of utterance. However, if the antecedent proposition is not prominent at the time the addressee did something else, the reproach is not present. See Biezma 2011a for details and experimental results.

20 Conventionalization would not really be a suitable account anyway, since not every instance of inverted conditionals in English and Spanish, not even in the case of HPCs, conveys a reproach.

21 What is optional is to have a numeration with or without a complementizer. If the complementizer is not in the numeration, inversion is not optional. 
some kind of pragmatic meaning. To reinforce the truth of a proposition, for example, we place a pitch accent on the auxiliary and achieve verum focus (Yes, I DO like movies) (see e.g. Romero \& Han 2004). An operation on the auxiliary is thus a recognized way to mark the information status of an element in the clause. In the case of inversion in conditional antecedents, we find something of the same nature: doing something to the auxiliary is a mechanism to mark information status in some way. In the case of inverted antecedents, it is a mechanism to mark the antecedent as GIVEN. Inversion signals the link between utterances and discourse.

Auxiliary inversion is an operation in which something is moved to the front (the auxiliary). This goes well with what we know about languages like English. In the same way that there is a tendency to mark new information by placing it towards the end of the sentence, we mark given information by pushing something to the front. Inversion in conditional antecedents is not the only operation of this sort. Framing adverbs and topicalization operations involve locating elements towards the front too. As a matter of fact, it seems that it is a feature of languages in which the verb follows the subject to mark old information by placing constituents at the front (Ward \& Birner 2004: footnote 1). If placing old information at the front is part of the strategies deployed by language for marking information status, we would expect the meaning of inversion to be derived from it. When there are two possible word-orders with the same truth-conditions, as in the case of inverted and non-inverted antecedents, we may expect to distinguish them by the information status of the constituents.

In sum, the fact that inversion in conditional antecedents indicates that the antecedent proposition has been entertained may fall out from general principles of language related to word-order. Movement from $\mathrm{T}$ to $\mathrm{C}$ in conditional antecedents conveys this meaning in several languages, such as Spanish and English. Indeed, based on what we know about these two languages, if an operation were meant to carry this meaning, this would be a perfect candidate. It goes well with what we know about how these languages mark information status.

The question we are left with is how such meanings are encoded in the grammar. At what level of representation should we posit this kind of meaning contribution? The meaning carried by inversion does not contribute to the truth-conditions of the utterance and it does not necessarily appeal to known information. Yet we know that this syntactic operation imposes constraints on the discourse. This means that a particular syntactic operation triggers pragmatic information without altering the semantic meaning. Although the syntax-semantics interface has been object of much research, and there is a great current interest in semantics-discourse interaction, not much has been said about the syntax-pragmatics interface. Further research may 
Biezma

show the need to consider how to deal with 'constructions' (Prince 1996). ${ }^{22}$

\section{References}

Anderson, Alan. 1951. A note on subjunctive and counterfactual conditionals. Analysis 12. 35-38.

Bhatt, Rajesh \& Roumiana Pancheva. 2006. Conditionals. In The Blackwell Companion to Syntax, vol. 1, 638-687. Oxford, England: Blackwell.

Biezma, María. 2010. Inverted antecedents in hidden conditionals. In Seda Kan, Claire Moore-Cantwell \& Robert Staub (eds.), Proceedings of North East Linguistics Society $40^{\text {th }}$, Amherst, MA: GLSA.

Biezma, María. 2011a. Anchoring Pragmatics in Syntax and Semantics. Amherst, MA: University of Massachusetts Amherst dissertation. Ms.

Biezma, María. 2011b. Optatives: Deriving desirability from scalar alternatives, 117-132. In Ingo Reich et al. Proceedings of Sinn \& Bedeutung 15.

Birner, B. J. \& G. Ward. 1998. Information status and noncanonical word order in english. Amsterdam/Philadelphia: John Benjamins.

Birner, Betty. 2006. Inferential relations and noncanonical word order. In Gregory Ward Betty Birner (ed.), Drawing the Boundaries of Meaning: Neo-Gricean Studies in Pragmatics and Semantics in Honor of Laurence R. Horn, 31-51. Amsterdam: John Benjamins.

Bosque, Ignacio. 1980. Retrospective Imperatives. Linguistic Inquiry 11(2). 415419.

Goodman, Nelson. 1947. The Problem of Counterfactual Conditionals. In F. Jackson (ed.), Conditionals, 9-27. New York: Oxford University Press.

Heim, Irene. 1982. The semantics of definite and indefinite Noun Phrases: University of Massachusetts, Amherst dissertation.

Horn, Lawrence. 2000. Pick a Theory (Not Just Any Theory). In Lawrence Horn \& Yasuhiko Kato (eds.), Negation and Polarity, 147-192. New York: Oxford Univerisity Press.

Iatridou, Sabine \& David Embick. 1994. Conditional Inversion. In Proceedings of north east linguistic society $24^{\text {th }}, 189-203$. UMass, Amherst: GLSA.

Kratzer, Angelika. 1977. What 'must' and 'can' must and can mean. Linguistics and Philosophy 1. 337-355.

Lambrecht. 1994. Information Structure and Sentence Form. Cambridge: Cambridge University Press.

Lewis, David. 1973. Counterfactuals. Oxford: Basil Blackwell.

22 I thank an anonymous reviewer for inspiration regarding this last point. 
Pesetsky, David. 1989. Language Particular Processes and the Earliness Principle. Ms. MIT.

Prince, Ellen. 1981. Toward a Taxonomy of Given-New information. In P. Cole (ed.), Radical pragmatics, 223-256. New York: Academic Press.

Prince, Ellen F. 1992. The ZPG letter: Subjects, definiteness and information structure. In William Mann Sandra Thompson (ed.), Discourse description: Diverse analyses of a fundraising text, 295-325. Philadelphia: John Benjamins. Prince, Ellen F. 1996. Constructions and the syntax-discourse interface. Ms., UPenn. Rawlins, Kyle. 2008. (Un)conditionals: an investigation in the syntax and semantics of conditional structures. Santa Cruz: University of California Santa Cruz dissertation. Ms.

Romero, Maribel \& Chung-Hye Han. 2004. On Negative Yes-No Questions. Linguistics and Philosophy 27. 609-658.

Schwarzschild, Roger. 1999. Givenness, AVOIDF and Other Constraints on the Placement of Accent. Natural Language Semantics 7. 141-177.

Veltman, Frank. 2005. Making counterfactual assumptions. Journal of Semantics 22. 159-180.

Ward, Gregory \& Betty Birner. 2004. Information structure and non-canonical syntax. In Kawrence R. Horn \& Gregory Ward (eds.), The handbook of pragmatics, Malden, MA: Blackwell Publishing.

María Biezma

150 Hicks Way, South College \#226

Linguistics Department, UMass Amherst

Amherst, MA, 01003

maria@linguist.umass.edu 